\title{
Circadian variation in tamoxifen pharmacokinetics in mice and breast cancer patients
}

\author{
Lisette Binkhorst ${ }^{1,2} \cdot$ Jacqueline S. L. Kloth ${ }^{1}$ Annelieke S. de Wit ${ }^{3}$. \\ Peter de Bruijn ${ }^{1}$ - Mei H. Lam ${ }^{1} \cdot$ Ines Chaves $^{3}$ - Herman Burger ${ }^{1}$. \\ Robbert J. van Alphen ${ }^{4}$ Paul Hamberg ${ }^{5}$ - Ron H. N. van Schaik ${ }^{6}$. \\ Agnes Jager $^{1}$ - Birgit C. P. Koch ${ }^{2}$ - Erik A. C. Wiemer ${ }^{1} \cdot$ Teun van Gelder ${ }^{2,7}$. \\ Gijsbertus T. J. van der Horst ${ }^{3} \cdot$ Ron H. J. Mathijssen ${ }^{1}$
}

Received: 24 February 2015/ Accepted: 25 May 2015/Published online: 7 June 2015

(c) The Author(s) 2015. This article is published with open access at Springerlink.com

\begin{abstract}
The anti-estrogen tamoxifen is characterized by a large variability in response, partly due to pharmacokinetic differences. We examined circadian variation in tamoxifen pharmacokinetics in mice and breast cancer patients. Pharmacokinetic analysis was performed in mice, dosed at six different times (24-h period). Tissue samples were used for mRNA expression analysis of drug-metabolizing enzymes. In patients, a cross-over study was performed. During three 24-h periods, after tamoxifen dosing at 8 a.m., 1 p.m., and 8
\end{abstract}

Electronic supplementary material The online version of this article (doi:10.1007/s10549-015-3452-x) contains supplementary material, which is available to authorized users.

Lisette Binkhorst

1.binkhorst@erasmusmc.nl

Gijsbertus T. J. van der Horst

g.vanderhorst@erasmusmc.nl

1 Department of Medical Oncology, Erasmus MC Cancer Institute, P.O. Box 2040, 3000 CA Rotterdam,

The Netherlands

2 Department of Hospital Pharmacy, Erasmus University Medical Center, P.O. Box 2040, 3000 CA Rotterdam, The Netherlands

3 Department of Genetics, Erasmus University Medical Center, P.O. Box 2040, 3000 CA Rotterdam, The Netherlands

4 Department of Internal Medicine, TweeSteden Ziekenhuis, P.O. Box 90107, 5000 LA Tilburg, The Netherlands

5 Department of Internal Medicine, Sint Franciscus Gasthuis, P.O. Box 10900, 3004 BA Rotterdam, The Netherlands

6 Department of Clinical Chemistry, Erasmus University Medical Center, P.O. Box 2040, 3000 CA Rotterdam, The Netherlands

7 Department of Internal Medicine, Erasmus University Medical Center, P.O. Box 2040, 3000 CA Rotterdam, The Netherlands p.m., for at least 4 weeks, blood samples were collected for pharmacokinetic measurements. Differences in tamoxifen pharmacokinetics between administration times were assessed. The mRNA expression of drug-metabolizing enzymes showed circadian variation in mouse tissues. Tamoxifen exposure seemed to be highest after administration at midnight. In humans, marginal differences were observed in pharmacokinetic parameters between morning and evening administration. Tamoxifen $C_{\max }$ and area under the curve (AUC) $)_{0-8 \mathrm{~h}}$ were $20 \%$ higher $(P<0.001)$, and tamoxifen $t_{\max }$ was shorter $(2.1$ vs. $8.1 \mathrm{~h} ; P=0.001)$, indicating variation in absorption. Systemic exposure $\left(\mathrm{AUC}_{0-24 \mathrm{~h}}\right)$ to endoxifen was $15 \%$ higher $(P<0.001)$ following morning administration. The results suggest that dosing time is of marginal influence on tamoxifen pharmacokinetics. Our study was not designed to detect potential changes in clinical outcome or toxicity, based on a difference in the time of administration. Circadian rhythm may be one of the many determinants of the interpatient and intrapatient pharmacokinetic variability of tamoxifen.

Keywords Tamoxifen - Endocrine therapy - Breast cancer $\cdot$ Circadian variation $\cdot$ Pharmacokinetics

\section{Introduction}

Tamoxifen belongs to the selective estrogen receptor modulators, and has been used extensively in the treatment of hormone receptor-positive breast cancer since its introduction. The drug acts as an estrogen receptor antagonist in breast tissue and has been shown to be beneficial in reducing the risk of disease recurrence and breast cancer mortality in the adjuvant setting as well as prolonging survival in patients with metastatic disease [1,2]. However, 
its use is characterized by large inter-individual variability in response, and non-response is observed in $30-50 \%$ of the patients. One of the mechanisms that may underlie the variable clinical response to tamoxifen is variability in pharmacokinetics [1-3].

Tamoxifen is considered a pro-drug and undergoes extensive biotransformation into various metabolites, catalyzed by phase I (cytochrome P450; CYP) and phase II (UDP-glucuronosyltransferases, sulfotransferases) metabolizing enzymes [4]. In humans, the parent compound is largely metabolized into $\mathrm{N}$-desmethyltamoxifen, and to a lesser extent into active 4-hydroxytamoxifen. Both metabolites can be further metabolized into 4-hydroxy- $N$-desmethyltamoxifen (endoxifen), which is thought to be the pharmacologically most important metabolite as it has a higher estrogen receptor affinity than the mother compound and reaches higher systemic levels than 4-hydroxytamoxifen [4, 5]. Several CYP enzymes are involved in the metabolism of tamoxifen, including CYP2D6, CYP3A4, CYP2C9, and CYP2C19, of which CYP2D6 is the main enzyme for endoxifen formation. Tamoxifen and its metabolites are subsequently metabolized into other phase I metabolites and conjugates and eliminated through the bile, feces, and urine $[4,6]$.

Endoxifen is considered to be responsible for the clinical effects of tamoxifen therapy. As recently suggested, a minimum threshold concentration for endoxifen should be attained to benefit from tamoxifen therapy [7]. Reduced endoxifen formation has been observed in tamoxifen-treated individuals carrying CYP2D6 variant alleles and with the concomitant use of CYP2D6-inhibiting medications [8]. Both factors have also been associated with clinical outcome in tamoxifentreated breast cancer patients, although the results of these studies have been inconsistent [9-12]. However, endoxifen formation not only depends on CYP2D6, as other enzymes, including CYP3A4 and CYP2C9, appear to be important as well. CYP3A4*22 genotype and concomitant medication that alters CYP3A4 enzyme activity have both been shown to affect tamoxifen pharmacokinetics [13, 14]. In addition to these factors, which contribute to inter-individual pharmacokinetic variability, tamoxifen pharmacokinetics may also differ within patients, known as intra-individual variability. In this way, circadian rhythms may influence tamoxifen pharmacokinetics.

Many biochemical and physiological processes in organisms, including animals and humans, follow day-night rhythms. These daily rhythms are generated by an internal timing system known as the circadian clock. Circadian variations in gastrointestinal functions, hepatic and intestinal enzyme activity and organ blood flow may all affect absorption, distribution, metabolism, and elimination of drugs, including tamoxifen. Accordingly, depending on the time of drug administration, endoxifen concentrations may vary, which is possibly important for the efficacy of tamoxifen therapy and occurrence of adverse effects [15-17].

Here, we investigated circadian variation in the pharmacokinetics of tamoxifen in mice and breast cancer patients. Circadian changes in plasma and organ exposure to tamoxifen and its metabolites were studied in FVB mice, which were orally administered tamoxifen at six different times over a 24-h period. Additionally, we examined circadian rhythms in mRNA levels of essential CYP enzymes in tissues of FVB mice. To evaluate circadian variation in pharmacokinetics of tamoxifen in breast cancer patients, we examined three different administration times: morning (8 a.m.), afternoon (1 p.m.), and evening (8 p.m.).

\section{Methods}

\section{Animals and synchronization}

One-hundred twenty-six female FVB mice with an age of 8-12 weeks were used in the experiments. Animals were housed under standardized conditions with a room temperature of $22{ }^{\circ} \mathrm{C}$, relative humidity of $55 \%$, and food and water ad libitum. For logistic reasons, the mice were kept in two rooms, under either a normal or inverted $12 \mathrm{~h}$ light/ $12 \mathrm{~h}$ dark regime (light 8 a.m. -8 p.m. and dark 8 p.m. -8 a.m. and vice versa). The animal experiments were approved by DEC consult, an independent Animal Ethical Committee (Dutch equivalent of the IACUC) and performed in accordance with local guidelines.

\section{Study in mice}

Tamoxifen was dissolved in peanut oil at a concentration of $4 \mathrm{mg} / \mathrm{ml}$, which was freshly prepared before each administration time. At six different time points, at 8 a.m., noon, 4 p.m., 8 p.m., midnight, and 4 a.m. (taking into account normal and inverted light/dark regimes), a fixed dose of $4 \mathrm{mg}$ tamoxifen ( $\sim 200 \mathrm{mg} / \mathrm{kg}$ bodyweight) was administered orally by gavage into the stomach to a group of 18 mice. Mice were fasted for $3 \mathrm{~h}$ prior to tamoxifen administration to minimize variation in absorption. Under anesthesia with isoflurane, blood samples were collected from the orbital sinus at 1, 2, 3, 5, 10, and $20 \mathrm{~h}$ after tamoxifen administration. Three mice were sacrificed per time point. After cervical dislocation, liver and small intestine (proximal, middle, and distal part) were quickly removed. Sample preparation and storage and pharmacokinetic analysis are described in the Supplementary Material. 
In a control group of 18 mice, administered solvent orally by gavage, plasma, liver and small intestine samples were collected every $4 \mathrm{~h}$ in a $24-\mathrm{h}$ period (3 mice/time point). Rhythmic mRNA expression of CYP enzymes was examined in mouse liver and three consecutive parts of the small intestine (see Supplementary Material). Expression of components of the circadian clock [Period 2 (Per2), Dbp, Bmal1, Cryptogene 1 (Cryl) and Rev-erb-a] was also determined, indicating the proper light entrainment of the mice.

\section{Patients}

Women using tamoxifen for breast cancer once daily for at least 4 months (to guarantee steady state) were included in the study. Additional eligibility criteria included age $>18$ years, WHO performance score $\leq 1$, normal blood cell counts, and adequate renal and hepatic functions. The use of (herbal) supplements was not allowed during the whole study period. During clinical days, patients received standard hospital meals, served at 7.30 a.m., noon, and 5 p.m. The study was performed at the Erasmus MC Cancer Institute, Rotterdam, The Netherlands. The Local Ethics Committee approved the study protocol (Dutch Trial Registry; NTR3473) and the study was conducted in accordance with the Declaration of Helsinki. All participants provided written informed consent before study entry.

\section{Clinical study}

This was a pharmacokinetic cross-over study, analyzing up to three different dosing times of tamoxifen. At the start of the study, patients were using tamoxifen once daily at an oral dose of 20 or $40 \mathrm{mg}$ either in the morning or evening. Due to the prolonged period for reaching steady state levels of tamoxifen metabolites, randomization was impractical, and patients were allocated to one of the two sequences (starting in morning or evening), depending on the time of tamoxifen administration before the study. After at least 4 weeks of dosing at either 8 a.m. or 8 p.m., pharmacokinetic profiles of tamoxifen and its metabolites were assessed during a 24-h period. Patients were then switched to the other time of administration for at least 4 weeks followed by a second pharmacokinetic blood sampling period. The third time of pharmacokinetic blood sampling occurred after 4 weeks of tamoxifen dosing in the afternoon (1 p.m.). On each study day, blood samples for hematological and biochemical analysis were also obtained. In addition, information on adherence, dosing time, concomitant medication, and adverse effects was collected on the days of pharmacokinetic blood sampling. Blood sample collection, measurement of tamoxifen and its metabolites in plasma [18], calculation of pharmacokinetic parameters, genotyping, and statistical analysis were performed as described in the Supplementary Material.

\section{Results}

\section{Study in mice}

To evaluate potential circadian rhythms in CYP-mediated metabolism and the contribution to circadian variation in pharmacokinetics of tamoxifen, mRNA expression levels of CYP enzymes involved in the metabolism of tamoxifen were assessed in tissues of mice over a $24-\mathrm{h}$ period. The daily mRNA expression patterns of components of the circadian clock [Period 2 (Per2), Dbp, Bmall, Cryptogene 1 (Cryl) and Rev-erb-a], and drug-metabolizing enzymes (Cyp2d10, Cyp2d22 and Cyp3a11; orthologues of human CYP enzymes involved in tamoxifen metabolism) in mouse liver and small intestine (control group) are displayed in Supplementary Fig. 1. As expected, cosinor analysis, used for the evaluation of 24-h rhythmicity, showed circadian oscillation in mRNA expression of components of the circadian clock. According to cosinor analysis, the mRNA expression of Cyp2d10 and Cyp $2 d 22$ in mouse liver appeared to oscillate rhythmically with a period of $24 \mathrm{~h}(P \leq 0.0413)$. Highest expression levels of Cyp $2 d 10$ and $C Y P 2 d 22$ were observed at 4 a.m. (which was the active phase of the mice in the experiment) and lowest at 4 p.m. (resting phase), with peak-trough ratios of 1.5 and 2.9. Expression of Cyp3al1 mRNA showed 24-h variation in the proximal part of the small intestine in mice $(P=0.0172)$, and transcript levels peaked at midnight and were lowest at noon (peak-trough ratio 2.8).

We then examined circadian variation in plasma and organ exposure to tamoxifen and its metabolites in mice. The exposure to tamoxifen and its metabolites 4-hydroxytamoxifen (major metabolite in mice), $N$-desmethyltamoxifen and endoxifen in plasma, liver, and three consecutive parts of the small intestine for the six dosing time groups are presented in Supplementary Table 1. Mean plasma concentration-time curves for tamoxifen following six administration times are displayed in Fig. 1.

In mice, no significant differences in exposure to tamoxifen and its metabolites were observed in plasma or tissues after oral tamoxifen administration at six different time points in a 24-h period. Cosinor analysis did not show significant circadian rhythms in area under the curves (AUCs) of the compounds as a function of dosing time $(P \geq 0.1354)$. A 12 -h rhythm was also not found. However, although not statistically significant, a trend towards higher tamoxifen exposure in plasma and liver tissue, expressed as $\mathrm{AUC}_{0-\text { last }}$, was seen following administration at midnight, which is the period in which mice are most active (Fig. 2). 


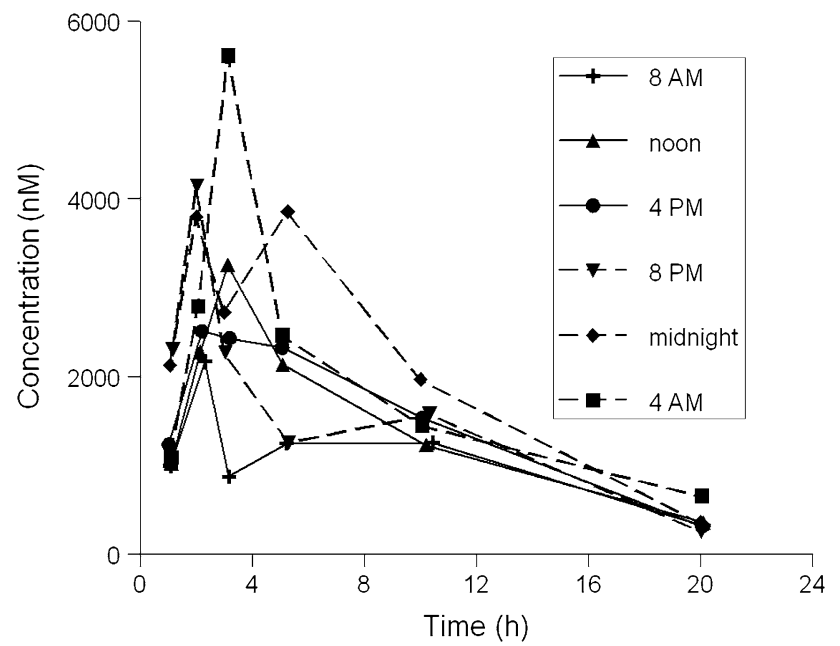

Fig. 1 Plasma concentration-time curves of tamoxifen following drug administration at six different times in a 24-h period in mice. Tamoxifen was administered to mice at a dose of $4 \mathrm{mg}$ by gavage at six different time points. Blood samples were collected at 1, 2, 3, 5, 10 , and $20 \mathrm{~h}$ after tamoxifen administration ( 3 mice/time point)

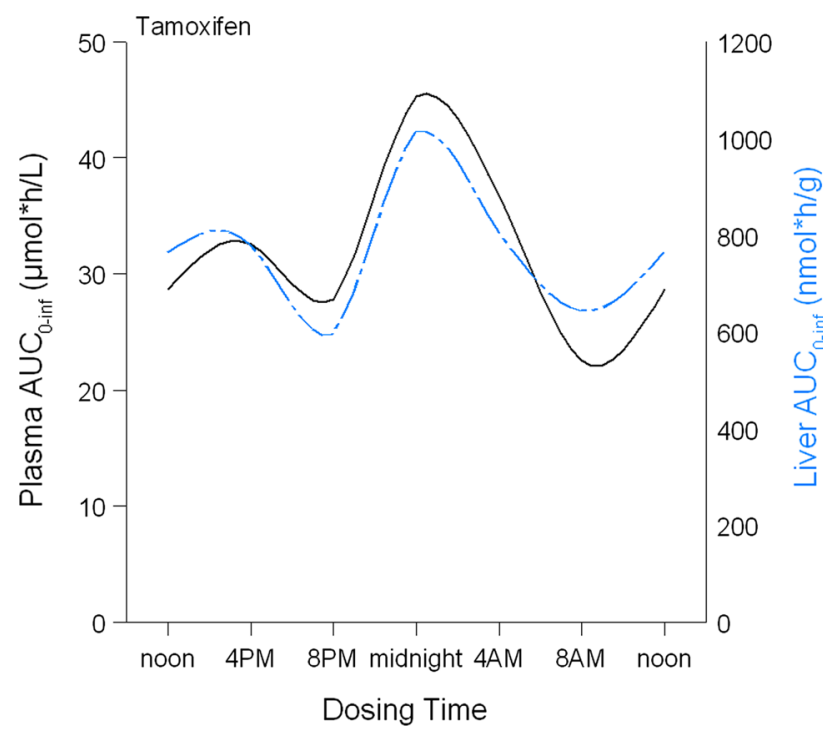

Fig. 2 Exposure to tamoxifen $\left(\mathrm{AUC}_{0-\mathrm{last}}\right)$ in plasma and liver tissue of mice following tamoxifen administration at six different times. Tamoxifen was administered to 18 mice at six different time points. Blood was collected at six time points (3 mice/time point) after tamoxifen administration and area under the curves $\left(\mathrm{AUCs}_{0-\mathrm{last}}\right)$ was calculated. Data are presented as $\mathrm{AUC}_{0 \text {-inf }}(y$-axis), derived from noncompartmental analysis on plasma concentration-time profiles of tamoxifen following dosing at six different times in a 24-h period $(x$ axis)

\section{Clinical study}

Twenty-seven women with hormone receptor-positive breast cancer completed two study periods: administration of tamoxifen in the morning ( 8 a.m.) and in the evening (8 p.m.). Of these patients, 12 women completed the third period of tamoxifen administration in the afternoon (1 p.m.). Before study entry, tamoxifen was used by 17 women in the morning $(63 \%)$, and by 10 women in the evening $(37 \%)$. Twenty-six patients received tamoxifen at a single dose of $20 \mathrm{mg}$; one woman received $40 \mathrm{mg}$ for metastatic disease. The mean age of the study participants was $53 \pm 9$ years, and the mean BMI was $27.5 \pm 4.7 \mathrm{~kg} /$ $\mathrm{m}^{2}$.

Adverse events observed in this study included hot flashes $(n=25)$, mood swings $(n=5)$, joint pain $(n=5)$, and weight gain $(n=3)$, which are all known side effects of tamoxifen. No serious adverse events occurred during the study period. Hematological and biochemical parameters were not statistically or clinically relevant different between the days of pharmacokinetic blood collection and none of the patients showed signs of disturbed liver or kidney function.

Concerning differences between morning and evening administration $(n=27)$, the mean plasma concentrationtime profiles and pharmacokinetic parameters for tamoxifen and its metabolites are presented in Fig. 3 and Table 1, respectively. Small but significant differences were observed in pharmacokinetic parameters of tamoxifen and its three major metabolites between morning and evening administration. For tamoxifen, the $\mathrm{AUC}_{0-8 \mathrm{~h}}$ and $C_{\max }$ were $20 \%(P<0.001)$ higher, and $t_{\max }$ was shorter after administration in the morning compared to evening dosing. Other pharmacokinetic parameters did not significantly differ between morning and evening administration. For endoxifen, the $\mathrm{AUC}_{0-8 \mathrm{~h}}$ and $C_{\max }$ were both $23 \%$ higher $(P<0.001)$ following morning administration compared to evening administration. However, the difference in the $\mathrm{AUC}_{0-24} \mathrm{~h}$ was small $[15 \%(P<0.001)]$.

The metabolic ratios, endoxifen-to- $N$-desmethyltamoxifen, $N$-desmethyltamoxifen-to-tamoxifen, 4-hydroxytamoxifen-to-tamoxifen, and total metabolites-to-tamoxifen differed only 6-9\% between morning and evening administration.

In the subgroup of women who completed three periods of different administration times $(n=12)$, no significant differences in pharmacokinetic parameters or metabolic ratios for tamoxifen and its metabolites were observed between dosing in the afternoon versus morning or dosing in the afternoon versus evening (Fig. 4; Supplementary Table 2).

Results of genotyping for CYP polymorphisms are summarized in Table 2. Endoxifen systemic exposure was relatively low in women who were $C Y P 2 D 6$ poor metabolizer. Differences in endoxifen concentrations between morning and evening administration seemed to be greater in women having extensive CYP2D6 metabolism compared with women having decreased CYP2D6 metabolism. The effects of administration time on plasma concentrations of 
Fig. 3 Mean plasma concentration-time profiles for tamoxifen (a), endoxifen (b), $N$ desmethyltamoxifen (c), and 4-hydroxytamoxifen (d) following tamoxifen administration in the morning at 8 a.m. (open circles) and in the evening at 8 p.m. (closed circles) in 27 women with (a history) of breast cancer
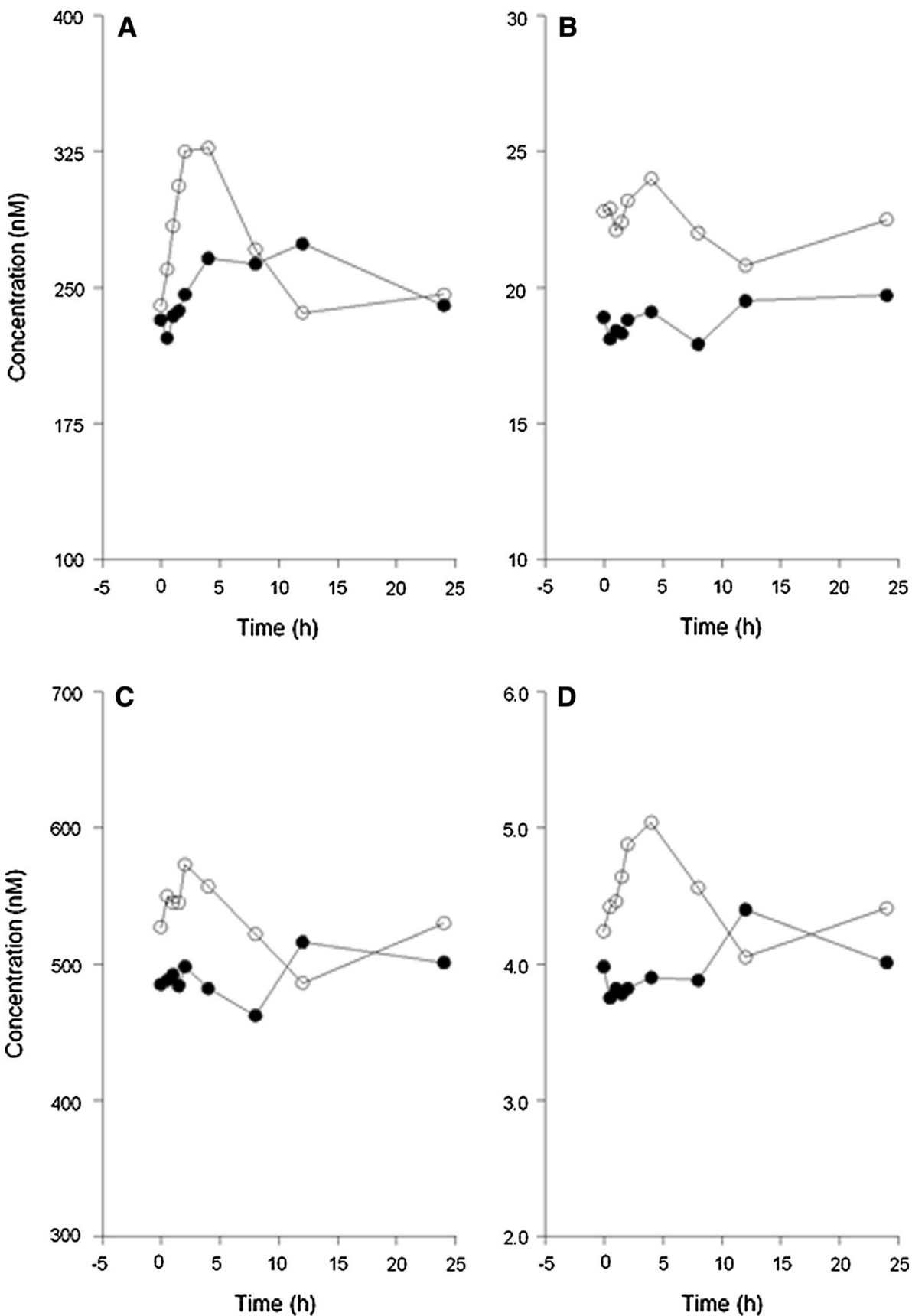

endoxifen or other metabolites did not vary according to CYP2C19 or CYP3A4 genotypes. However, the sample size was too small to detect differences between individuals with different genotypes.

\section{Discussion}

In the preclinical study, circadian variation in mRNA expression levels of CYP enzymes, Cyp2d10, Cyp2d22, and Cyp3a11, in mouse liver, and small intestine was observed, which is in accordance with the findings by Zhang et al. [19]. On the basis of mRNA expression levels, higher CYP enzyme activity could be expected during the active phase and lower activity during the resting phase.

We observed that exposure to tamoxifen appeared to be higher in mouse plasma and liver tissue after tamoxifen administration in the active phase, with the highest levels following administration at midnight, although differences were not statistically significant. However, a large variation in concentrations of tamoxifen and its metabolites between the individual mice was observed, which may be explained 
Table 1 Pharmacokinetic parameters for tamoxifen and its metabolites following administration in the morning (8 a.m.) and evening (8 p.m.) in 27 women

\begin{tabular}{|c|c|c|c|c|c|}
\hline & $\begin{array}{l}\text { Morning } \\
\text { administration } \\
(8 \text { a.m. })\end{array}$ & $\begin{array}{l}\text { Evening } \\
\text { administration } \\
(8 \text { p.m. })\end{array}$ & $\begin{array}{l}\text { Ratio } \\
\text { Morning versus } \\
\text { evening }\end{array}$ & $\begin{array}{l}\text { Difference }(95 \% \\
\text { confidence } \\
\text { interval) }\end{array}$ & $P$ value $^{\mathrm{c}}$ \\
\hline \multicolumn{6}{|l|}{ Tamoxifen } \\
\hline $\mathrm{AUC}_{0-8 \mathrm{~h}}(\mathrm{nmol} / \mathrm{l} \mathrm{h})$ & $2355 \pm 709$ & $1977 \pm 587$ & $1.20 \pm 0.16$ & $378(273,484)$ & $<0.001$ \\
\hline $\mathrm{AUC}_{0-24 \mathrm{~h}}(\mathrm{nmol} / \mathrm{l} \mathrm{h})$ & $6266 \pm 1853$ & $6138 \pm 1764$ & $1.03 \pm 0.11$ & $128(-133,389)$ & 0.324 \\
\hline$C_{24 \mathrm{~h}}(\mathrm{nmol} / \mathrm{l})$ & $246 \pm 88.5$ & $240 \pm 75.1$ & $1.04 \pm 0.21$ & $6.60(-12.8,26.0)$ & 0.491 \\
\hline$C_{\max }(\mathrm{nmol} / \mathrm{l})$ & $356 \pm 107$ & $298 \pm 84.2$ & $1.20 \pm 0.20$ & $58.0(38.1,77.8)$ & $<0.001$ \\
\hline$t_{\max }(\mathrm{h})$ & $2.1(1.0-24.0)$ & $8.1(1.5-24.0)$ & & & 0.001 \\
\hline$t_{1 / 2}(\mathrm{~h})^{\mathrm{a}}$ & $48.0 \pm 32.3$ & $76.3 \pm 51.0$ & $0.86 \pm 0.64$ & $-28.4(-58.1,1.36)$ & 0.060 \\
\hline CL/F (1/h) & $9.40 \pm 3.17$ & $9.55 \pm 3.04$ & $0.99 \pm 0.11$ & $-0.16(-0.59,0.28)$ & 0.471 \\
\hline \multicolumn{6}{|l|}{ ND-tamoxifen } \\
\hline $\mathrm{AUC}_{0-8 \mathrm{~h}}(\mathrm{nmol} / \mathrm{l} \mathrm{h})$ & $4081 \pm 1576$ & $3496 \pm 1263$ & $1.16 \pm 0.13$ & $584(400,768)$ & $<0.001$ \\
\hline $\mathrm{AUC}_{0-24 \mathrm{~h}}(\mathrm{nmol} / \mathrm{l} \mathrm{h})$ & $11,891 \pm 4280$ & $11,092 \pm 4017$ & $1.08 \pm 0.13$ & $799(316,1283)$ & 0.002 \\
\hline$C_{24 \mathrm{~h}}(\mathrm{nmol} / \mathrm{l})$ & $519 \pm 210$ & $476 \pm 176$ & $1.09 \pm 0.17$ & $43.5(8.99,78.0)$ & 0.015 \\
\hline$C_{\max }(\mathrm{nmol} / \mathrm{l})$ & $615 \pm 235$ & $536 \pm 207$ & $1.16 \pm 0.19$ & $78.9(44.9,113)$ & $<0.001$ \\
\hline$t_{\max }(\mathrm{h})$ & $2.1(0.5-24.2)$ & $4.1(0.5-24.2)$ & & & 0.019 \\
\hline \multicolumn{6}{|l|}{ 4OH-tamoxifen } \\
\hline $\mathrm{AUC}_{0-8 \mathrm{~h}}(\mathrm{nmol} / \mathrm{l} \mathrm{h})$ & $35.6 \pm 10.6$ & $28.6 \pm 9.20$ & $1.28 \pm 0.30$ & $7.01(4.85,9.19)$ & $<0.001$ \\
\hline $\mathrm{AUC}_{0-24 \mathrm{~h}}(\mathrm{nmol} / \mathrm{l} \mathrm{h})$ & $101 \pm 30.0$ & $92.8 \pm 30.6$ & $1.12 \pm 0.24$ & $8.50(3.18,13.83)$ & 0.003 \\
\hline$C_{24 \mathrm{~h}}(\mathrm{nmol} / \mathrm{l})$ & $4.24 \pm 1.24$ & $3.86 \pm 1.35$ & $1.14 \pm 0.24$ & $0.37(0.10,0.65)$ & 0.010 \\
\hline$C_{\max }(\mathrm{nmol} / \mathrm{l})$ & $5.26 \pm 1.63$ & $4.43 \pm 1.48$ & $1.25 \pm 0.49$ & $0.823(0.356,1.29)$ & 0.001 \\
\hline$t_{\max }(\mathrm{h})$ & $4.0(0.5-24.0)$ & $12.0(1.0-24.1)$ & & & 0.001 \\
\hline \multicolumn{6}{|l|}{ Endoxifen } \\
\hline $\mathrm{AUC}_{0-8 \mathrm{~h}}(\mathrm{nmol} / \mathrm{l} \mathrm{h})$ & $179 \pm 84.3$ & $144 \pm 61.9$ & $1.23 \pm 0.14$ & $34.9(23.4,46.4)$ & $<0.001$ \\
\hline $\mathrm{AUC}_{0-24 \mathrm{~h}}(\mathrm{nmol} / \mathrm{l} \mathrm{h})$ & $524 \pm 245$ & $453 \pm 203$ & $1.15 \pm 0.13$ & $70.6(45.4,95.7)$ & $<0.001$ \\
\hline$C_{24 \mathrm{~h}}(\mathrm{nmol} / \mathrm{l})$ & $22.5 \pm 10.2$ & $19.7 \pm 9.05$ & $1.16 \pm 0.20$ & $2.74(1.41,4.08)$ & $<0.001$ \\
\hline$C_{\max }(\mathrm{nmol} / \mathrm{l})$ & $27.2 \pm 12.5$ & $22.0 \pm 9.27$ & $1.23 \pm 0.21$ & $5.20(3.20,7.19)$ & $<0.001$ \\
\hline$t_{\max }(\mathrm{h})$ & $2.1(0.5-24.2)$ & $4.1(0.5-24.2)$ & & & 0.026 \\
\hline \multicolumn{6}{|l|}{ Metabolic ratio } \\
\hline Metab/tamoxifen ${ }^{\mathrm{b}}$ & $2.01 \pm 0.33$ & $1.90 \pm 0.32$ & $1.06 \pm 0.078$ & $0.11(0.053,0.16)$ & $<0.001$ \\
\hline
\end{tabular}

Data are presented as mean and standard deviation. $t_{\max }$ expressed as median and range. Parameters of one patient using 40 mg tamoxifen were dose-corrected to $20 \mathrm{mg}$

$N D$-tam $\mathrm{N}$-desmethyltamoxifen, $4 \mathrm{OH}$-tam 4-hydroxytamoxifen, Metab metabolites, $\mathrm{AUC}$ area under the curve, $\mathrm{C}_{24} \mathrm{~h}$ concentration before dosing $(t=24 \mathrm{~h}) ; C_{\max }$ maximum concentration, $t_{\max }$ time to reach $C_{\max }, t_{1 / 2}$ elimination half-life, $C L / F$ apparent oral clearance

${ }^{\text {a }}$ Based on results of 19 patients

${ }^{\mathrm{b}} \mathrm{AUC}_{0-24 \mathrm{~h}}$ ratio of ND-tamoxifen, 4-OH-tamoxifen, and endoxifen-tamoxifen

${ }^{\mathrm{c}}$ Paired Student's $t$-test $\left(t_{\max }\right.$ Wilcoxon signed-rank test)

by several factors. First, the animals were given a fixed dose of $4 \mathrm{mg}$ tamoxifen and small differences in bodyweight of the mice may have contributed to the variability in pharmacokinetics. In addition, tamoxifen was dissolved in peanut oil and given by oral gavage, which also may have influenced the absorption in mice.

In the exploratory clinical study, the pharmacokinetic parameters of tamoxifen and its metabolites differed slightly between morning and evening administration. The tamoxifen $C_{\max }$ and $\mathrm{AUC}_{0-8 \mathrm{~h}}$ were both higher after morning administration and $t_{\max }$ was reached earlier, suggesting an increased absorption rate following morning dosing compared with evening dosing. These results complement previous findings of more rapid absorption of lipophilic drugs after administration in the morning [15]. The underlying mechanisms of a higher absorption rate in the early morning involve faster gastric emptying, higher gastrointestinal motility, and higher gastrointestinal blood 
Fig. 4 Individual changes in plasma exposure $\left(\mathrm{AUC}_{0-24 \mathrm{~h}}\right)$ and maximum concentrations $\left(C_{\max }\right)$ for tamoxifen $(\mathbf{a}, \mathbf{b})$ and endoxifen $(\mathbf{c}, \mathbf{d})$ after tamoxifen administration at three different times; morning (8 a.m.), afternoon ( 1 p.m.), and evening (8 p.m.) in 12 women. For two patients, $\mathrm{AUC}_{0-24 \mathrm{~h}}$ data (1 p.m.) were lacking
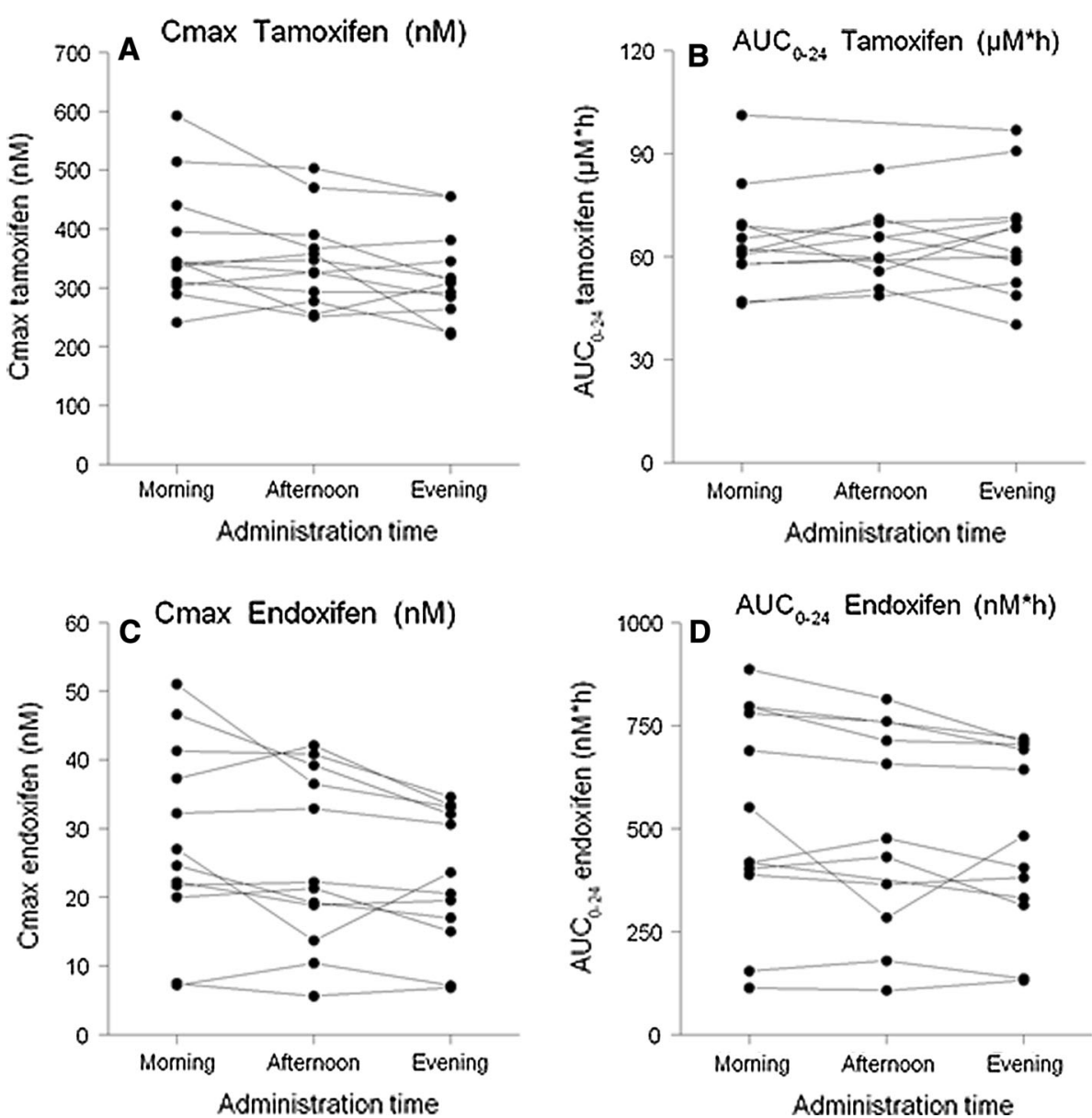

Table 2 Results of genotyping for cytochrome P450 polymorphisms

\begin{tabular}{llc}
\hline Genes & Alleles & Number $(\%)^{\mathrm{a}}$ \\
\hline CYP2D6 & EM & $15(58)$ \\
& IM & $8(31)$ \\
CYP2C19 & PM & $3(11)$ \\
& $* 1 / * 1$ & $13(50)$ \\
& $* 1 / * 2$ & $6(23)$ \\
& $* 1 / * 17$ & $2(8)$ \\
& $* 2 / * 2$ & $1(4)$ \\
& $* 2 / * 17$ & $4(15)$ \\
CYP3A4 & $* 1 / * 1$ & $10(39)$ \\
& $* 1 / * 22$ & $12(46)$ \\
& $* 22 / * 22$ & $4(15)$ \\
\hline
\end{tabular}

$E M$ two active alleles, $I M$ one non-functional allele or two decreased function alleles, $P M$ two non-functional alleles

${ }^{a}$ Results of one individual were missing

flow in the morning than in the evening [20-22]. In addition, since higher gastric acidity lowers lipophilic drug absorption, the absorption of these drugs is generally lower in the evening due to increased gastric acid secretion at that moment of the day [23].

Slightly higher $C_{\max }$ and $\mathrm{AUC}_{0-8} \mathrm{~h}$ values and shorter $t_{\max }$ were also observed for the metabolites following morning dosing compared with evening dosing. The endoxifen $\mathrm{AUC}_{0-24 \mathrm{~h}}$ was also significantly higher following morning dosing than following evening dosing; however, the actual difference was only minor. Despite the higher metabolite concentrations, the difference in metabolic ratios of the three metabolites-to-tamoxifen between morning and evening dosing was small and clinically irrelevant ( $\sim 6 \%)$, implying that the increase in metabolite concentrations is not associated with major changes in CYP-mediated metabolism. The higher tamoxifen concentrations due to increased absorption in the early morning have probably contributed to the slightly higher metabolite levels.

In the subgroup of 12 women who completed three cycles of different dosing times, no relevant differences in pharmacokinetic parameters of tamoxifen and its metabolites were observed after drug administration in the afternoon compared with administration in the morning or evening. However, it seemed that the plasma exposure to tamoxifen 
and its three metabolites following administration in the afternoon was slightly higher than that observed after evening dosing but a little lower than after morning administration. This may be explained by the fact that the sleep/ wakefulness cycle is the most important rhythm in humans and influences physiological functions [16]. Therefore, the greatest variation in processes, such as gastric emptying, gastrointestinal motility, and gastric acid secretion, could be expected between morning and evening.

In the preclinical study, plasma and liver exposure to tamoxifen appeared to be highest following administration at midnight. The results are in line with the observation of higher plasma levels of tamoxifen after dosing at 8 a.m., the start of the active phase in humans. However, in humans, dosing in the afternoon did not result in the highest exposure to tamoxifen and its metabolites. Differences in physiological processes between mice and humans may be a plausible explanation for this discrepancy. In addition, we observed circadian variation in mRNA expression levels of CYP enzymes in mouse liver and intestine. Circadian variation of hepatic CYP3A4 activity in humans has been assumed from the observation of a 2.8 -fold mean diurnal variation in the $6 \beta$-hydroxycortisol-to-cortisol ratio as a marker of CYP3A4 activity [24]. Although differences in tamoxifen pharmacokinetics in humans are probably due to variation in absorption, the influence of circadian variation in metabolism cannot be totally excluded. Metabolic ratios did not show relevant differences between morning and evening dosing; however, this might be explained by circadian variation in elimination of tamoxifen metabolites through glucuronidation by UDP-glucuronosyltransferases [25]. However, we did not measure glucuronides of tamoxifen and its metabolites. A trend towards greater differences in endoxifen exposure between morning and evening administration in women with extensive CYP2D6 metabolism, according to genotype, was observed, which might suggest a possible influence of circadian variation in (CYP2D6) metabolism.

The study was not designed to detect potential differences in efficacy of tamoxifen treatment or side effects between the different administration times. However, the small changes in tamoxifen pharmacokinetics between morning and evening administration are likely not relevant for the efficacy of tamoxifen. A number of women reported changes in incidence and severity of hot flashes during the study, which may indicate a possible relation between the time of tamoxifen administration and occurrence of hot flashes. Possibly, the occurrence of hot flashes is associated with peak plasma concentrations of tamoxifen or one of its metabolites [26]. However, this could not be established in this study.

Although to a lesser degree than other factors (i.e., CYP2D6 genetic polymorphisms, co-medication), circadian rhythms contribute to interpatient and intrapatient pharmacokinetic variability of tamoxifen. Therefore, dosing time may be relevant in clinical studies and possibly for applying therapeutic drug monitoring, which has been proposed for individualization of tamoxifen therapy [27]. In the last years, many studies have been undertaken to identify genetic and environmental factors which may contribute to the inter-individual variability in pharmacokinetics $[4,8,13]$. Currently, the majority of studies focus on the relationship between CYP2D6 genotype, endoxifen concentrations, and clinical outcome or toxicity $[7,28]$. However, most studies do not take into account the time of tamoxifen administration and the time of blood collection (intra-individual circadian variation), which may contribute to increased variability. Trough samples are not always collected [7, 8], as the long elimination half-life of tamoxifen and $\mathrm{N}$-desmethyltamoxifen suggest no large differences in concentrations. However, the results of this study suggest that the time of tamoxifen administration as well as sampling time may be relevant and should be taken into consideration in studies relating endoxifen concentrations and clinical outcome.

Potential limitations of our study include the lack of standardization of waking and sleeping hours of the study participants and standardization of the meals. Although the meals were not strictly controlled, it is unlikely that this may have influenced the results of the study given that food has not been shown to affect the pharmacokinetics of tamoxifen [29]. In addition, meals were served on fixed times (at 7.30 a.m., noon, and 5 p.m.), with the time of dinner in the evening $3 \mathrm{~h}$ before tamoxifen administration, making the influence of food on the pharmacokinetics even more unlikely.

\section{Conclusions}

The present study shows that differences in dosing time (i.e., morning vs. evening) lead to small differences in tamoxifen pharmacokinetics, probably not relevant for the efficacy of the drug. To minimize additional interpatient and intrapatient pharmacokinetic variability, administration time should be taken into consideration in studies relating endoxifen concentrations and clinical outcome and possibly in therapeutic drug monitoring for therapy individualization.

Acknowledgments We thank Anna Pagani, Anne-Joy de Graan, Annemieke Nieuweboer, Cindy Bolder, Dennis de Meulder, Dominique Kuiper, Ellen de Morree, Els Moltzer, Inge Ghobadi Moghaddam-Helmantel, Patricia van Kuijk, Stefanie Vester, Ton Boersma and Xander den Dekker for their specific contribution to this study.

Conflict of interest The authors declare that they have no conflict of interest. 
Ethical approval All procedures performed in studies involving human participants were in accordance with the ethical standards of the Institutional and/or National Research Committee and with the 1964 Helsinki Declaration and its later amendments or comparable ethical standards. All applicable international, national, and/or institutional guidelines for the care and use of animals were followed. All procedures performed in studies involving animals were in accordance with ethical standards of the institution or practice at which the studies were conducted.

Informed consent Informed consent was obtained from all individual participants included in the study.

Open Access This article is distributed under the terms of the Creative Commons Attribution-NonCommercial 4.0 International License (http://creativecommons.org/licenses/by-nc/4.0/), which permits any noncommercial use, distribution, and reproduction in any medium, provided you give appropriate credit to the original author(s) and the source, provide a link to the Creative Commons license, and indicate if changes were made.

\section{References}

1. Early Breast Cancer Trialists' Collaborative Group (2005) Effects of chemotherapy and hormonal therapy for early breast cancer on recurrence and 15-year survival: an overview of the randomised trials. Lancet 365:1687-1717. doi:10.1016/S0140-6736(05)66544-0

2. Hoskins JM, Carey LA, McLeod HL (2009) CYP2D6 and tamoxifen: DNA matters in breast cancer. Nat Rev Cancer 9:576-586. doi:10.1038/nrc2683

3. Schiavon G, Smith IE (2013) Endocrine therapy for advanced/ metastatic breast cancer. Hematol Oncol Clin N Am 27:715-736, viii. doi:10.1016/j.hoc.2013.05.004

4. Murdter TE, Schroth W, Bacchus-Gerybadze L, Winter S, Heinkele G, Simon W, Fasching PA, Fehm T, German T, Group AIC, Eichelbaum M, Schwab M, Brauch H (2011) Activity levels of tamoxifen metabolites at the estrogen receptor and the impact of genetic polymorphisms of phase I and II enzymes on their concentration levels in plasma. Clin Pharmacol Ther 89:708-717. doi:10.1038/clpt.2011.27

5. Stearns V, Johnson MD, Rae JM, Morocho A, Novielli A, Bhargava P, Hayes DF, Desta Z, Flockhart DA (2003) Active tamoxifen metabolite plasma concentrations after coadministration of tamoxifen and the selective serotonin reuptake inhibitor paroxetine. J Natl Cancer Inst 95:1758-1764

6. Lien EA, Solheim E, Lea OA, Lundgren S, Kvinnsland S, Ueland PM (1989) Distribution of 4-hydroxy- $N$-desmethyltamoxifen and other tamoxifen metabolites in human biological fluids during tamoxifen treatment. Cancer Res 49:2175-2183

7. Madlensky L, Natarajan L, Tchu S, Pu M, Mortimer J, Flatt SW, Nikoloff DM, Hillman G, Fontecha MR, Lawrence HJ, Parker BA, Wu AH, Pierce JP (2011) Tamoxifen metabolite concentrations, CYP2D6 genotype, and breast cancer outcomes. Clin Pharmacol Ther 89:718-725. doi:10.1038/clpt.2011.32

8. Borges S, Desta Z, Li L, Skaar TC, Ward BA, Nguyen A, Jin Y, Storniolo AM, Nikoloff DM, Wu L, Hillman G, Hayes DF, Stearns V, Flockhart DA (2006) Quantitative effect of CYP2D6 genotype and inhibitors on tamoxifen metabolism: implication for optimization of breast cancer treatment. Clin Pharmacol Ther 80:61-74. doi:10.1016/j.clpt.2006.03.013

9. Schroth W, Goetz MP, Hamann U, Fasching PA, Schmidt M, Winter S, Fritz P, Simon W, Suman VJ, Ames MM, Safgren SL, Kuffel MJ, Ulmer HU, Bolander J, Strick R, Beckmann MW,
Koelbl H, Weinshilboum RM, Ingle JN, Eichelbaum M, Schwab M, Brauch H (2009) Association between CYP2D6 polymorphisms and outcomes among women with early stage breast cancer treated with tamoxifen. JAMA 302:1429-1436. doi:10. 1001/jama.2009.1420

10. Lash TL, Cronin-Fenton D, Ahern TP, Rosenberg CL, Lunetta KL, Silliman RA, Garne JP, Sorensen HT, Hellberg Y, Christensen M, Pedersen L, Hamilton-Dutoit S (2011) CYP2D6 inhibition and breast cancer recurrence in a population-based study in Denmark. J Natl Cancer Inst 103:489-500. doi:10.1093/jnci/ djr010

11. Aubert RE, Yao J, Teagarden JR, Subar M, Epstein RS, Skaar TC, Desta Z, Flockhart DA (2009) Risk of breast cancer recurrence in women initiating tamoxifen with CYP2D6 inhibitors. J Clin Oncol 27(suppl):18 s (abstr CRA508)

12. Rae JM, Drury S, Hayes DF, Stearns V, Thibert JN, Haynes BP, Salter J, Sestak I, Cuzick J, Dowsett M, Trialists A (2012) CYP2D6 and UGT2B7 genotype and risk of recurrence in tamoxifen-treated breast cancer patients. J Natl Cancer Inst 104:452-460. doi:10.1093/jnci/djs126

13. Teft WA, Gong IY, Dingle B, Potvin K, Younus J, Vandenberg TA, Brackstone M, Perera FE, Choi YH, Zou G, Legan RM, Tirona RG, Kim RB (2013) CYP3A4 and seasonal variation in vitamin D status in addition to CYP2D6 contribute to therapeutic endoxifen level during tamoxifen therapy. Breast Cancer Res Treat 139:95-105. doi:10.1007/s10549-013-2511-4

14. Binkhorst L, van Gelder T, Loos WJ, de Jongh FE, Hamberg P, Moghaddam-Helmantel IM, de Jonge E, Jager A, Seynaeve C, van Schaik RH, Verweij J, Mathijssen RH (2012) Effects of CYP induction by rifampicin on tamoxifen exposure. Clin Pharmacol Ther 92:62-67. doi:10.1038/clpt.2011.372

15. Baraldo M (2008) The influence of circadian rhythms on the kinetics of drugs in humans. Expert Opin Drug Metab Toxicol 4:175-192. doi:10.1517/17425255.4.2.175

16. Paschos GK, Baggs JE, Hogenesch JB, FitzGerald GA (2010) The role of clock genes in pharmacology. Annu Rev Pharmacol Toxicol 50:187-214. doi:10.1146/010909.105621

17. Ohdo S, Koyanagi S, Matsunaga N, Hamdan A (2011) Molecular basis of chronopharmaceutics. J Pharm Sci 100:3560-3576. doi:10.1002/jps.22656

18. Binkhorst L, Mathijssen RH, Ghobadi Moghaddam-Helmantel IM, de Bruijn P, van Gelder T, Wiemer EA, Loos WJ (2011) Quantification of tamoxifen and three of its phase-I metabolites in human plasma by liquid chromatography/triple-quadrupole mass spectrometry. J Pharm Biomed Anal 56:1016-1023. doi:10.1016/ j.jpba.2011.08.002

19. Zhang YK, Yeager RL, Klaassen CD (2009) Circadian expression profiles of drug-processing genes and transcription factors in mouse liver. Drug Metab Dispos 37:106-115. doi:10.1124/dmd. 108.024174

20. Goo RH, Moore JG, Greenberg E, Alazraki NP (1987) Circadian variation in gastric emptying of meals in humans. Gastroenterology 93(3):515-518

21. Kumar D, Wingate D, Ruckebusch Y (1986) Circadian variation in the propagation velocity of the migrating motor complex. Gastroenterology 91:926-930

22. Lemmer B, Nold G (1991) Circadian changes in estimated hepatic blood flow in healthy subjects. Br J Clin Pharmacol 32:627-629

23. Moore JG, Englert E Jr (1970) Circadian rhythm of gastric acid secretion in man. Nature 226:1261-1262

24. Ohno M, Yamaguchi I, Ito T, Saiki K, Yamamoto I, Azuma J (2000) Circadian variation of the urinary 6beta-hydroxycortisol to cortisol ratio that would reflect hepatic CYP3A activity. Eur J Clin Pharmacol 55:861-865

25. Zheng Y, Sun D, Sharma AK, Chen G, Amin S, Lazarus P (2007) Elimination of antiestrogenic effects of active tamoxifen 
metabolites by glucuronidation. Drug Metab Dispos 35:1942-1948. doi:10.1124/dmd.107.016279

26. Lorizio W, Wu AH, Beattie MS, Rugo H, Tchu S, Kerlikowske K, Ziv E (2012) Clinical and biomarker predictors of side effects from tamoxifen. Breast Cancer Res Treat 132:1107-1118. doi:10. 1007/s10549-011-1893-4

27. Gao B, Yeap S, Clements A, Balakrishnar B, Wong M, Gurney H (2012) Evidence for therapeutic drug monitoring of targeted anticancer therapies. J Clin Oncol 30:4017-4025. doi:10.1200/ JCO.2012.43.5362

28. Saladores P, Murdter T, Eccles D, Chowbay B, Zgheib NK, Winter S, Ganchev B, Eccles B, Gerty S, Tfayli A, Lim JS, Yap
YS, Ng RC, Wong NS, Dent R, Habbal MZ, Schaeffeler E, Eichelbaum M, Schroth W, Schwab M, Brauch H (2014) Tamoxifen metabolism predicts drug concentrations and outcome in premenopausal patients with early breast cancer. Pharmacogenomics J. doi:10.1038/tpj.2014.34

29. Singh BN, Malhotra BK (2004) Effects of food on the clinical pharmacokinetics of anticancer agents: underlying mechanisms and implications for oral chemotherapy. Clin Pharmacokinet 43:1127-1156. doi:10.2165/00003088-200443150-00005 